\title{
A aplicabilidade do dano moral à pessoa jurídica*
}

\section{Applicability of moral damages to entity}

André de Paula Viana'

* Artigo recebido em agosto de 2013. Aceito para publicação em junho de 2014.

${ }^{1}$ Graduado em ciências jurídicas e sociais, especialista, mestrando, professor universitário na Universidade Camilo Castelo Branco.

\section{Resumo}

Pela busca da evolução social via da adequação da norma legal, o denominado Novo Código Civil, em seu artigo 52 a ampliação da proteção aos direitos da personalidade também às pessoas jurídicas. O Código Civil, como assim mencionado, buscou adequação aos novos parâmetros sociais, via de respaldo constitucional pela admissão da legitimidade da pessoa jurídica para a postulação ativa de reparação por danos morais. Por se tratar de importante inovação legal, causa a pacificação da jurisprudência, porém e d'outro norte causará euforia na doutrina mais ativa, bem como pelo livre convencimento dos magistrados nos pretórios nacionais.

Palavras-chave: Responsabilidade Civil; Direitos da personalidade; Dano Moral da pessoa jurídica.

\begin{abstract}
For the search of the social evolution saw of the adequacy of the rule of law, called the New Civil Code, in its article 52 the magnifying of the protection to the rights of the personality also to the legal people. The Civil Code, as thus mentioned, searched adequacy to the new social parameters, way of constitutional endorsement for the admission of the legitimacy of the legal entity for the active postulation of repairing for pain and suffering. For if dealing with important legal innovation, cause the pacification of the jurisprudence, however and of another north will cause euphoria in the doctrine most active, as well as for judicial discretion of the magistrates in the national courts of law.
\end{abstract}

Keywords: Civil liability; Rights of the personality; Pain and suffering of the legal entity. 


\section{Introdução}

Em um contexto em extrema e dinâmica mutação, iniciamos considerações intimamente ligadas a responsabilidade civil. Visto que todos nós buscamos o equilíbrio entre o justo e do injusto; a equidade pacifica e difusa entre o que é justo e o que é direito.

No curso da evolução social/legal, o próprio conceito de "pessoa", sofre alteração face à ocorrência e criação da figura da pessoa jurídica pela pessoa física. Visto que para primeira existir, adquirir direitos e personalidade jurídica; carece de atuação da segunda.

Por adquirir direitos, possuir personalidade jurídica e patrimônio próprio; e mesmo assim ser subjetiva e abstrata, a pessoa jurídica pode sofrer em tese muitos dos danos que até então eram inerentes às pessoas físicas.

Outrora existente com exclusividade das pessoas físicas, contemporaneamente o foco se volta para as pessoas jurídicas à necessidade de reparação por danos morais.

Por ser necessária; recentemente o instituto da reparação civil por danos morais foi incluído expressamente na legislação infraconstitucional, com a entrada em vigor da Lei $\mathrm{n}^{\circ} 10.406 / 2002$, pela qual foi instituído o Novo Código Civil.

Por maciça maioria, surge da livre convicção dos magistrados de primeira instância em seus julgados, reconhecendo a legitimidade ativa das pessoas jurídicas para demandarem a devida reparação por danos morais que lhe forem causados.

Via de hermenêutica interpretação de cada caso em concreto a ser julgado; paulatinamente serão fixados conceitos mais exatos a serem utilizados para a pacificação do tema.

\section{Essência do dano moral e correlação as pesso- as jurídicas}

A prima facie, via do tema a ser exposto; a grande problemática é se de fato a pessoa jurídica pode sofrer dano moral ou não, visto ao que se refere à pessoa física, também denominada de pessoa natural a pacificação sobre o tema é inerente a sua própria existência.

A Carta Magna em seu artigo 5o, incisos V e X, assegurou a indenização pelo dano material e moral à pessoa física, vejamos:

\section{TÍTULO II \\ Dos Direitos e Garantias Fundamentais CAPÍTULO DOS DIREITOS E DEVERES IN- DIVIDUAIS E COLETIVOS}

Art. $5^{\circ}$ Todos são iguais perante a lei, sem distinção de qualquer natureza, garantindo-se aos brasileiros e aos estrangeiros residentes no País a inviolabilidade do direito à vida, à liberdade, à igualdade, à segurança e à propriedade, nos termos seguintes:

(...)

V - é assegurado o direito de resposta, proporcional ao agravo, além da indenização por dano material, moral ou à imagem;

(...)

$\mathrm{X}$ - são invioláveis a intimidade, a vida privada, a honra e a imagem das pessoas, assegurado o direito a indenização pelo dano material ou moral decorrente de sua violação; ${ }^{2}$

Ao que tange sobre a possibilidade da pessoa jurídica, se esta pode sofrer dano moral, considerações ainda restam a ser feitas, visto que a pessoa jurídica por ser abstrata, ou seja, uma figura legal causa estranheza a muitos poder sofrer dano moral, visto que este, por seu sentido estrito.

Considera-se dano moral quando uma pessoa se acha afetada em seu ânimo psíquico, moral e intelectual, seja por ofensa à sua honra, na sua privacidade, intimidade, imagem, nome ou em seu próprio corpo físico, e poderá estender-se ao dano patrimonial se a ofensa de alguma forma impedir ou dificultar atividade profissional da vítima.

O dano moral corresponderia às lesões sofridas pela pessoa humana, consistindo em violações de natureza não econômica. É quando um bem de ordem moral, como a honra, é maculado. ${ }^{3}$

Para que possamos entender as novíssimas aplicabilidades e possibidades do dano moral em seu a strito senso, notadamente devemos conhecer sua origem histórica, qual remonta possivelmente nos Códigos de Manu e Hammurabi.

\footnotetext{
2 http://www.planalto.gov.br/ccivil_03/constituicao/constitui\%C3\%A7ao.htm

3 http://pt.wikipedia.org/wiki/Dano_moral
} 
Por volta do segundo milênio, antes da era cristã, num período anterior ao próprio Direito romano, o Código de Hamurabi já disciplinava algumas situações na Mesopotâmia em que o dano de natureza moral poderia ser reparado pecuniariamente. Apesar da predominância do preceito "olho por olho e dente por dente" da lei do Talião, que expressava o direito da vingança da vítima para retribuir na mesma proporção o dano causado, havia casos especiais em que a imposição de uma pena econômica constituía outra forma quase que alternativa de se proporcionar à vítima uma satisfação compensatória em pagamento de "ciclos de prata", excluindo-se a vindita. Assim, os babilônios estabeleciam penalidades pecuniárias para os casos de dano moral, e somente quando estes meios eram frustrados, é que se aplicava a pena de talião.

Há quem diga que as leis sumerianas, como o Código de Ur-Nammu (três séculos mais antigo que o de Hamurábi), previa um número maior de fatos em que o direito da vindita já teria sido substituído pela reparação compensatória, através de uma compensação pecuniária em determinadas situações, adotando assim o princípio da reparabilidade dos atualmente chamados danos morais.

No entanto, para o jurista Wilson Melo da Silva, as leis antigas da Mesopotâmia, bem como o Código de Manu, na Índia, não tiveram a manifesta intenção de se referirem, nesta parte, de modo positivo e expresso ao dano moral. Embora não tivesse dispensado a regra do Talião, a lei de Moisés também adotou algumas soluções quanto à reparação por danos morais, conforme se observa neste texto em Deuteronômio 22:13,19 - Bíblia, em que a vítima sofre uma indiscutível humilhação.

Se um homem desposar uma mulher e, depois de coabitar com ela, a aborrecer, e lhe imputar delitos vergonhosos, e contra ela divulgar má fama, dizendo: Tomei esta mulher, e me cheguei a ela, porém não a achei virgem, os pais da moça tomarão as provas da virgindade dela, e as levarão aos anciãos da cidade, à porta. $\mathrm{O}$ pai da moça dirá aos anciãos: Dei minha filha por mulher a este homem, porém ele a aborreceu, e lhe imputou delitos vergonhosos dizendo: Não achei tua filha virgem. Então os pais estenderão a roupa dela diante dos anciãos da cidade, os quais tomarão aquele homem e o castigarão. Condená-lo-ão em cem ciclos de prata, e o entregarão ao pai da moça, porque divulgou má fama sobre uma virgem de
Israel. Ela continuará a ser sua mulher e ele não poderá, andá-la embora enquanto viver.

Entre os gregos, desde os tempos homéricos, a compensação financeira por danos morais constituía-se como uma tradição. As normas instituídas pelo Estado aboliram o direito de vingança privada e determinavam que a reparação do dano poderia ser de natureza pecuniária.

No Direito Romano, a Lei das XII Tábuas previa penas patrimoniais para crimes como dano e injúria e furto.

Todavia, até hoje há controvérsias entre os pesquisadores se a idéia de reparação por danos morais era conhecida ou não pelos romanos. Porém, renomados pesquisadores internacionais, como foi Rudolf von Ihering, defendem que a reparação do dano moral, assim como a maior parte das instituições de direito privado, teria suas fontes no Direito romano.

$\mathrm{Na}$ "actio injuriarum aestimatoria", o injuriado podia pleitear perante o magistrado uma certa soma em satisfação pelas injúrias sofridas, ficando, entretanto, livre o juiz decidir se o pedido era justo e eqüitativo.

Segundo o jurisconsulto Domitius Ulpianus, a injúria seria o que não se faz de direito. Em outras palavras, tudo aquilo que se faz sem direito era considerado como injúria de um modo geral.

Assim, no Direito romano, entre as quatro espécies de delitos privados, havia a "injuria" e o "damnum injuria datum" (dano produzido pela injúria) que foi regulado pela "Lex Aquilia”. Enquanto, na “injuria”, se tinha em conta o homem, considerado apenas física ou moralmente, no "damnum injuria datum", se visava de maneira precípua, o seu patrimônio. Assim, a essência do "damnum injuria datum" seria a diminuição patrimonial da vítima, o que tornava necessária a sua reparação.

Como já foi dito, a Lei das XII Tábuas apresentava inicialmente apenas três modalidades de injúrias e que, com o decorrer do tempo, tornaram-se ineficazes para acompanhar a dinâmica social do povo romano. $\mathrm{E}$ o princípio da Lei de Talião foi se tornando aos poucos incompatível com o período clássico.

Com a adoção da "actio de iniuriis aestimandis", os recuperadores (juízo colegiado) estavam autorizados a fixarem multas conforme os seus próprios critérios de 
justiça e equidade. $\mathrm{O}$ prazo para a vítima propor a ação pretoriana era de um ano, sob pena de prescrição e, se a reclamação fosse julgada indevida, o réu poderia requerer do autor o pagamento da décima parte do valor do pedido formulado. Mesmo após a queda do Império Romano, os procedimentos da ação pretoriana repercutiram por muitos séculos, influenciando, inclusive, as Ordenações do Reino de Portugal.

A Idade Média foi marcada pela adoção do então Direito canônico, o qual teve larga influência no território brasileiro e nas Ordenações Filipinas em virtude da força da religião católica na época. Embora mantivesse procedimentos oriundos do Direito romano, o Código Canônico foi valorado conforme os dogmas da Igreja Católica e estabelecia sansões de ordem material e espiritual para determinadas condutas.

Nas Ordenações Filipinas, em relação à estimativa do próprio dano subjetivo, verifica-se indícios da adoção parcial do procedimento romano na parte que especificamente diz respeito ao chamado "valor de afeição".

Importante ressaltar que, por influência do Direito canônico, até a vigência do Código Civil brasileiro de 1916 (Lei n. 3.071), vigorava o instituto dos esponsais, onde se previa que a recusa do noivo em se casar, sem um justo motivo, importaria na sua condenação em perdas e danos, sendo, portanto, mais uma manifestação do que se convencionou chamar de danos morais. Por sua vez, as Ordenações Filipinas já previam uma reparação pecuniária pela sedução de mulher virgem (Título XXIII do Livro V), caso o homem não se casasse com ela e o Título XXXVIII do Livro III prescrevia que, em hipótese de demanda por dívida já paga, deveria ser procedida a restituição em dobro do valor recebido.

Apesar das conquistas humanistas trazidas pela Revolução Francesa, muitas das legislações civis modernas não contemplaram expressamente o instituto do dano moral; diversos foram os entendimentos jurisprudenciais e doutrinários sobre a sua aplicação.

O Código Civil de Napoleão Bonaparte não delineou de forma expressa os limites da reparabilidade do dano moral. O seu artigo 1.382 apenas estabeleceu que o causador do dano tem a obrigação de repará-lo, desde que configurada a sua culpabilidade, passando uma noção bem ampla do instituto que tanto poderia abranger as lesões de ordem material ou não patrimonial. Ficava assim, ao critério do intérprete da lei dizer se o dommage poderia ou não ser empregado em seu sentido lato, devendo ser registrado que houve um acolhimento favorável em inúmeras hipóteses pelos tribunais franceses no decorrer da história contemporânea.

Tal como o Código napoleônico, o artigo 1.151 do Código Civil italiano, de 1865, adotou texto semelhante. Porém, a princípio, os juízes reduziam os casos de reparação por danos morais a um número bem insignificante e muitos eram os doutrinadores que negavam a reparabilidade. E, somente quando passou a vigorar o Código Penal de 1930, cujo artigo 185 assegurava a reparação à vítima por todo crime praticado contra ela ou sua família, começou a prevalecer o entendimento de que ambos os dispositivos das leis civil e criminal deveriam ser interpretados em conjunto, ainda que o fato tenha sido um ilícito civil.

Da mesma maneira, o Código Civil espanhol de 1890 , em vigor até hoje, repetiu a disposição contida no Código Civil francês. Porém, ao contrário do que ocorreu na França, o dano não foi interpretado abrangentemente. A jurisprudência e a doutrina espanhola entendiam que o artigo 1.902 da Lei Civil se referia tão somente ao dano patrimonial, entendendo não ser valorável a honra. E, por longos anos, os Tribunais não souberam fazer a exata distinção entre os danos materiais e morais.

Nota-se que o Código napoleônico teve uma grande importância para as legislações elaboradas no mundo contemporâneo. Não só o antigo Código Civil italiano, como as leis civis de outros países, a exemplo de Espanha e Portugal, editadas em fins do século XIX, receberam a influência direta da França.

Em 1900, com o surgimento do BGB - Burgerliches Getsetzbuch, ou Código Civil alemão, foi criado um novo sistema de reparação por danos morais, em que a condenação do réu só poderia ser admitida dentro das hipóteses taxativamente enumeradas em lei (parágrafo 253 do Código).

A influência do BGB nas legislações do século XX foi surpreendente. A própria Itália, através do atual Código Civil de 1942, passou a adotar o sistema limitativo da reparação por danos morais, limitação esta que não era prevista no anterior Código de 1865 . Contudo, as hipóteses de incidência ficaram reduzidas exatamente àquelas nas quais o dano resulte da prática de um crime, de acordo com o artigo 185 do Código Penal italiano de 1930, 
obrigando a doutrina e a jurisprudência a contornarem os casos não contemplados em lei.

No Brasil, além das previsões específicas das Ordenações Filipinas já mencionadas, o Código Criminal de 1830 dispunha que a indenização seria sempre a mais completa possível, mas sem fazer nenhuma alusão à reparação do dano moral. Tal dispositivo foi depois reproduzido pelo artigo 800 da Consolidação das Leis Civis de Augusto Teixeira de Freitas, o qual definia o dano como "o mal, que resultar à pessoa e aos bens do ofendido" (art. 801) que deveria ser avaliado por árbitros em toda a sua extensão.

O Código Penal brasileiro de 1890, em seu artigo 276, por sua vez, tratou de assegurar expressamente, a "prestação pecuniária satisfatória de dano moral, nos casos de atentado contra a honra da mulher" e determinava, em seu artigo 70, que nos demais casos a indenização fosse regulada pelo Direito Civil. Entretanto, muita polêmica foi levantada quanto à reparação prevista nesta lei, encarada incompreensivelmente na época como uma medida iníqua, vergonhosa e desmoralizadora.

O artigo 21 caput da Lei n. ${ }^{\circ}$ 2.681, de 7 de dezembro de 1912, que regulou a responsabilidade civil nas estradas de ferro, dispunha que "no caso de lesão corpórea ou deformidade", além das perdas e danos, das despesas do tratamento da vítima e dos lucros cessantes, o juiz deve arbitrar "uma indenização conveniente".

Contudo, a reparabilidade por danos morais, mesmo depois da vigoração do Código Civil de 1916, só era reconhecida nos casos de acidentes ferroviários. O Supremo Tribunal Federal, quando decidia questões relativas a esses fatos, não fundamentava suas decisões no artigo 1.538 do Código Civil e sim no artigo 21 caput da Lei n. ${ }^{\circ}$ 2.681/12, negando aos familiares das vítimas a indenização por danos morais. Em alguns acórdãos o STF considerava não ser indenizável o valor afetivo exclusivo. Em outras decisões, o artigo 76 da Lei Civil era considerado como norma de natureza meramente processual. E, ainda houve julgamentos em que o dano moral só se tornaria indenizável caso a lesão produzisse reflexos patrimoniais para o ofendido.

Porém, a nova realidade social se impunha e, devido aos insistentes reclamos doutrinários, os tribunais foram paulatinamente renovando os seus entendimentos a fim de acompanharem as contingências da vida moderna. Houve então uma gradativa ampliação do conceito de dano moral indenizável, o que a princípio se verificou na valoração do dano material até se chegar à indubitável compreensão em favor da reparabilidade.

O Código Brasileiro de Telecomunicações marcou esse novo período de evolução do princípio da reparabilidade do dano moral. A Lei n. ${ }^{\circ}$ 4.117/62 tratava expressamente da regulamentação dos danos morais indiretos ou dos reflexos patrimoniais dos danos não econômicos. Os seus artigos 81 a 88 dispunham sobre o dano moral relativo às ofensas experimentadas por alguém em virtude de calúnia, difamação ou injúria, veiculadas por radiodifusão, ampliando, inclusive, as hipóteses de reparabilidade. Tais dispositivos, porém, vigoraram até a edição do Decreto-lei n. ${ }^{\circ} 236 / 67$ que, através de seu artigo $3^{\circ}$, revogou os artigos 58 a99 da referida lei.

Ainda durante a década de 60 foram aprovados o Código Eleitoral (Lei n. ${ }^{\circ}$ 4.737, de 15/07/1965) e a Lei de Imprensa (lei n. ${ }^{\circ}$ 5.250, de 09/02/1967), que tratavam expressamente da indenização por danos morais igualmente nos casos de calúnia, injúria e difamação.

A III Conferência Nacional de Desembargadores, ocorrida em dezembro de 1965, no extinto Estado da Guanabara, veio demonstrar as novas inclinações da magistratura brasileira para adaptar o Direito à realidade social quanto ao princípio da reparabilidae do dano moral, tornando-se um marco importante na evolução jurisprudencial. Passou-se daí a considerar que o dano moral deveria ser ressarcido também nas hipóteses em que não ocorresse nenhuma lesão patrimonial à vítima, somando inúmeras divergências existentes até então.

Com a promulgação da Constituição da República de 1988, foi definitivamente finalizada qualquer dúvida remanescente a respeito da reparabilidade pelo dano moral. $\mathrm{O}$ artigo $5^{\circ}$ da Carta Magna, em seus incisos $\mathrm{V}$ e $\mathrm{X}$, estatuiu a indenização pelo dano moral como sendo uma garantia dos direitos individuais.

$\mathrm{O}$ artigo $5^{\circ}$, item $\mathrm{V}$, assegura o direito de resposta proporcionalmente ao agravo, "além da indenização por dano material, moral ou à imagem".

Procurou o constituinte distinguir de maneira expressa as indenizações pelos danos materiais, morais e à imagem, não obstando a cumulatividade desses direitos, mesmo havendo também o exercício do direito de resposta.

Assim, o dano moral, mais do que nunca, tornou-se 
inconfundível com o dano de natureza patrimonial e tal distinção tem obrigado tanto a doutrina como a jurisprudência a identificar o que vem a ser o referido dano à imagem.

Hoje em dia, o dano moral é reconhecido e aplicado pela maioria dos países, devendo ser esclarecido que, em algumas legislações estrangeiras, ainda condicionam a compensação por lesões imateriais à configuração da redução patrimonial da vítima e que o Direito de alguns países, como a Rússia e a Hungria, por influência do marxismo-leninismo que marcou o período comunista da ex-URSS, ainda não admitem a indenização por danos morais.

Já o direito anglo-americano, em razão do particularíssimo sistema que se distingue dos países de direito codificado, os casos concretos decididos pelos tribunais vão compondo teorias que se tornam aplicáveis a futuras situações idênticas e passam a servir de fundamento analógico para questões semelhantes, sendo bem amplas e vultuosas as indenizações arbitradas pelos Tribunais. ${ }^{4}$

Pelo supracitado, podemos observar que o dano moral remonta à própria existência do ser humano, motivo pelo as interpretações, evoluções e adequações sociais sobre o tema foram necessárias à sua aplicabilidade também às pessoas jurídicas, visto que estas via de regra são criadas para o exercício coletivo da atividade empresarial. A pessoa jurídica se constitui pela vontade unilateral de uma pessoa fisica e deve ser registrada nos orgãos públicos competentes (Junta Comercial).

Pode-se dizer que a indenização por dano moral não tem como finalidade compensar a vítima pelo prejuízo sofrido. Seria, antes de tudo, uma punição ao ofensor, não podendo ultrapassar proporções que afetem sua subsistência, mas deve servir como exemplo para que tal ato ilícito não seja mais cometido.

Dessa forma, o valor a ser pedido pela vítima não será, necessariamente, aquele sentenciado pelo juiz. Isso porque cabe ao magistrado conduzir com bom senso as questões concernentes a esse tema.

Sabe que não é possível quantificar o valor da moral ou da honra de um ser humano. Entretanto, sendo a honra, a privacidade, a intimidade e a imagem das pessoas protegidas pela lei, tais valores podem ficar a margem da proteção jurídica e nem gerar impunição aos seus violadores.

4 http://pt.wikipedia.org/wiki/Dano_moral
De qualquer modo, independentemente da aplicação do aspecto preventivo e pedagógico do instituto, faz-se necessária a configuração dos elementos básicos da responsabilidade civil, quais sejam: a conduta ilícita comissiva ou omissiva, o dano e o nexo de causalidade capaz de explicar que o prejuízo de natureza moral decorreu do fato praticado ou omitido pelo agente lesionador.

Hoje é pacífico o entendimentos dos tribunais de que o Dano Moral pode atingir tanto a pessoa física quanto a jurídica que de alguma forma sofre lesão em seu de interesse não patrimonial. ${ }^{5}$ (n.n.)

Em sendo certo o importe devido a título de danos materiais, visto que este é determinado ou pelo menos determinável, resta à análise tão somente sobre o dano moral, pois de fato há grande dificuldade em se fixar o valor da indenização condizente ao dano efetivamente sofrido tendo em vista que este é puramente subjetivo.

Haja vista ser subjetiva a natureza do dano moral, a forma de reparação mais utilizada é o pagamento de determinado importe à vitima, como medida coercitiva, impositiva, bem como pedagógica ao ofensor.

A boa reputação e a confiabilidade são atributos inerentes à personalidade das pessoas jurídicas.

D’outro norte demais legislações vigentes, pacificam o tema, vejamos:

\section{TÍTULO I \\ Dos Direitos do Consumidor CAPÍTULO I \\ Disposições Gerais \\ (...)}

Art. $2^{\circ}$ Consumidor é toda pessoa física ou jurídica que adquire ou utiliza produto ou serviço como destinatário final.

(...)

\section{CAPÍTULO III}

Dos Direitos Básicos do Consumidor

(...)

Art. $6^{\circ}$ São direitos básicos do consumidor:

(...)

VI - a efetiva prevenção e reparação de danos patrimoniais e morais, individuais, coletivos e difusos; ${ }^{6}($ n.n.)

5 http://pt.wikipedia.org/wiki/Dano_moral

6 LEI No 8.078, DE 11 DE SETEMBRO DE 1990. - Código de Defesa do Consumidor 
Observem que lidimo resta o fato de que a pessoa jurídica pode efetivamente ser considerada como consumidora de produtos ou serviços bem como buscar a prevenção ou reparação dos danos morais sofridos.

Em consenso com a norma legal reconheceu o $\mathrm{Su}-$ perior Tribunal de Justiça via de sua ilustrativa e balizadora jurisprudência, vejamos:

CIVIL. RESPONSABILIDADE CIVIL. DANOS MORAIS. PESSOA JURIDICA. POSSIBILIDADE. HONRA OBJETIVA. DOUTRINA. PRECEDENTES DO TRIBUNAL. RECURSO PROVIDO PARA AFASTAR A CARENCIA DA AÇÃO POR IMPOSSIBILIDADE JURIDICA. - A EVOLUÇÃO DO PENSAMENTO JURIDICO, NO QUAL CONVERGIRAM JURISPRUDENCIA E DOUTRINA, VEIO A AFIRMAR, INCLUSIVE NESTA CORTE, ONDE O ENTENDIMENTO TEM SIDO UNANIME, QUE A PESSOA JURIDICA PODE SER VITIMA TAMBEM DE DANOS MORAIS, CONSIDERADOS ESSES COMO VIOLADORES DA SUA HONRA OBJETIVA. ${ }^{7}$ (n.n.)

O Egrégio TJRS, tem adotado entendimento acerca do assunto, como se vê, por exemplo, em acórdão que tiveram como relatores os eminente Desembargadores Ruy Rosado de Aguiar Jr. e Arintides Albuquerque Neto, ambos admitindo a legitimidade ativa da pessoa jurídica para ser sujeito passivo do dano moral e pleitear a indenização correspondente, leia-se:

"Possuindo a pessoa jurídica legítimos interesses de ordem imaterial, embora não tenha psíquico próprio nem sinta dor, ela pode sofrer dano moral passível de reparação." (n.n.)

O Superior Tribunal de Justiça, dando a última palavra sobre o tema, vem contemplando a pessoa jurídica como parte legítima ativa para auferir direito a indenização por dano moral sofrido, tendo, inclusive, encerrado a controvérsia com a edição da Sumula no 227, vejamos: "A pessoa jurídica pode sofrer dano moral".

Como sobredito; a jurisprudência já vinha se inclinando para a permissibilidade dessa legitimidade ativa às pessoas jurídicas, tendo em vista o conteúdo normativo do artigo 5o, incisos V e X, da Constituição Federal, que não restringe a proteção do direito à honra somente às pessoas físicas, pelo que caberia, então, essa proteção

7 REsp 134993 / MA, RECURSO ESPECIAL, 1997/0039042-0

8 Apelação Civil no 587.064-718, TJRS, Relator Des. Ruy Rosado de Aguiar Jr. também às pessoas jurídicas, no que é possível, ou seja, no que se refere à proteção da honra objetiva.

Assim sendo, o artigo 52, do novo Código Civil possui a seguinte dicção: "Aplica-se às pessoas jurídicas, no que couber, a proteção dos direitos da personalidade."

Como referido, a doutrina já entendia como cabível a reparação do dano moral causado à pessoa jurídica, notadamente contra sua honra objetiva (direito da personalidade), pelo que diante do artigo 52 do Código Civil.

Em reforço ao tema, terá também a jurisprudência, que vem sendo franca nesse sentido:

RESPONSABILIDADE CIVIL - Danos morais - Pessoa jurídica. Ao adquirir personalidade, a pessoa jurídica faz jus à proteção legal e estatal à sua honra objetiva, considerada assim a reputação que goza em sua área de atuação. O dano moral puro é aquele em que a ofensa que lhe deu causa não traz reflexos patrimoniais, independendo, sua reparação, da existência de prejuízos econômicos oriundos do ataque irrogado. Recurso conhecido e improvido. ${ }^{10}$

Não há o que falar em equivalência entre o importe proveniente da indenização e o dano sofrido. Não se afigura possível, então, a reparação propriamente dita do dano, com retorno ao "status quo ante". Na impossibilidade de reparação equivalente, compensa-se dano moral com determinada quantia pecuniária, que funciona como lenitivo e forma alternativa para que o transtorno possa ser atenuado com as comodidades que o dinheiro pode proporcionar. A par disso, a condenação pecuniária também tem natureza punitiva, sancionando o causador do dano. Como corolário da sanção, surge ainda à função preventiva da indenização, pois esta deverá ser dimensionada de tal forma a desestimular o ofensor a repetição do ato ilícito.

É ressabido que o valor do dano moral deve ser estipulado na soma que compense a dor, o desconforto, os dissabores e a humilhação sofridos e represente ônus ao patrimônio do devedor, para que cesse a repetição de atos ofensivos à pessoa, seja física ou jurídica, adequando-se assim, perfeitamente a teoria do DESISTÍMULO das práticas proibidas por lei.

9 http://www.planalto.gov.br/ccivil_03/LEIS/2002/L10406. htm

10 TJDF - 3a Câm.; Ap. Cível n.o 41.293/96-DF; Rela. Desa. Nancy Andrighi; j. 04.11.1996; maioria de votos.; ementa. 
Assim, a condenação além de reparar o dano, deve também contribuir para desestimular a repetição de atos lesionadores da personalidade das pessoas jurídicas.

A somar-se ao direito exposto, citamos os ditames contidos nos artigos do Código Civil, in verbis:

Art. 186. Aquele que, por ação ou omissão voluntária, negligência ou imprudência, violar direito e causar dano a outrem, ainda que exclusivamente moral, comete ato ilícito.

Art. 187. Também comete ato ilícito o titular de um direito que, ao exercê-lo, excede manifestamente os limites impostos pelo seu fim econômico ou social, pela boa-fé ou pelos bons costumes.

\section{(...)}

Art. 927. Aquele que, por ato ilícito (arts. 186 e 187), causar dano a outrem, fica obrigado a repará-lo.

Parágrafo único. Haverá obrigação de reparar o dano, independentemente de culpa, nos casos especificados em lei, ou quando a atividade normalmente desenvolvida pelo autor do dano implicar, por sua natureza, risco para os direitos de outrem. ${ }^{11}$

\section{Considerações finais}

A pessoa jurídica, efetivamente pode ser vítima de dano em sua honra subjetiva, bem como objetiva, visto a existência de personalidade jurídica da mesma, qual se efetiva pelo efetivo registro desta no órgão estatal competente, ressalvado que precede a este ato a formalização da pessoa jurídica.

O supracitado dano via de regra, transfigura-se em dano de natureza patrimonial. Ao entorno do tema, ressalta-se que as pessoas jurídicas sem fins lucrativos, não sofrem esse abalo patrimonial, porém mesmo nesta circunstância podem ser vítimas de um dano moral. Não existe propriamente indenização por danos morais no caso das empresas jurídicas, por ser impossível a ocorrência de dor psicológica a ser mitigada, ocorrendo tão somente um abalo a existência da mesma, levando-se em consideração a questão dos bens incorpóreos que a compõe. Os valores desembolsados pelo causador do dano devem ser considerados como uma penalidade com função retributiva, pedagógica e exemplar.

\section{Referências}

Código Civil comentado: doutrina e jurisprudência: Lei n. 10.406, de 10.01.2002: contém o Código Civil de 1916/ coordenador Cesar Peluso - 3 ed. rev. e atual. - Barueri, SP: Manole, 2009.

Código de Processo Civil comentado: doutrina e jurisprudência: contém a lei do juizado especial cível comentada/ João Roberto Parizatto - 1 ed. - Leme, SP: Edipa - Editora Parizatto, 2008.

CAHALI, Yussef S. Dano moral. 2a ed. rev., atual. e ampl. São Paulo: Revista dos Tribunais, 2000.

COELHO, Fábio U. Curso de direito comercial. $5^{a}$ ed., revista e atualizada de acordo com o novo Código Civil e alterações da LSA. São Paulo: Saraiva, 2002, vol II.

DINIZ, Maria Helena: Curso de direito civil brasileiro, volume 7: responsabilidade civil/ Maria Helena Diniz. 23 ed. reformulada. - São Paulo: Saraiva, 2009.

RODRIGUES, Sílvio. Direito civil. $28^{a}$ ed. São Paulo: Saraiva, 1998, v. I. 